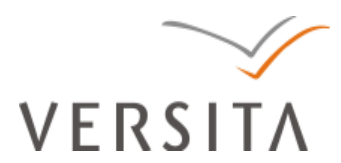

Folia Oeconomica Stetinensia

DOI: 10.2478/v10031-011-0021-2

\section{uSWNIEZ}

Wydzial Nauk Ekonomicznych i Zarządzania Uniwersytetu Szczecińskiego

\title{
ECONOMETRIC ANALYSIS OF THE IMPACT OF PROPENSITIES ON ECONOMIC OCCURRENCES: A MACROECONOMIC PERSPECTIVE
}

\author{
Mariusz Doszyń, Ph.D. \\ Department of Econometrics and Statistics \\ Faculty of Economics and Management \\ University of Szczecin \\ Mickiewicza 64, 71-101 Szczecin \\ e-mail: mariusz.doszyn@gmail.com
}

Received 6 June 2011, Accepted 14 December 2011

\begin{abstract}
The main aim of this article was the specification of problems connected with analysis of impact of human propensities on economic occurrences and also a proposition of econometric tools enabling the identification of this impact. According to the meaning of propensities in economics the current state of knowledge is mostly an effect of considerations presented by J.M. Keynes in his famous book "The General Theory of Employment, Interest and Money" where J.M. Keynes proposed such economic categories as the average and marginal propensities. One of the goals of the presented deliberations was to specify problems related with economic theory of propensities. Such propensities as a propensity to consume, to save, to invest and thesaurisation were particularly carefully analysed. The impact of these propensities on basic macroeconomic variables was considered with respect to the classical model, the neoclassical Solow-Swan model and the $I S-L M$ scheme. In case of spatial data the effects of the impact of propensities could be analysed by means of models with dummy variables showing presence of given propensities. A procedure enabling the construction of such variables was proposed. In case of time series, conceptions delivered by the integration and cointegration theory could be applied. Especially such models as VAR and VECM could be useful. Models for panel data enable direct (models with fixed effects) or indirect (models with random effects) consideration of the impact of propensities on the analysed processes.
\end{abstract}

Keywords: econometric analysis of the impact of human propensities, the Solow-Swan model, the $I S-L M$ scheme, VAR and VECM models, models for panel data.

JEL classification: B22, B40, C01, C22, C23, E20. 


\section{Introduction}

Most economic processes depend not only on objective factors such as income, prices, inflation, interest rates, but are also determined by subjective (psychological and sociological) causes. Objective factors are crucial but they should be corrected with respect to propensities and other psychological and sociological effects. The importance of psychological factors led to fast development of a new discipline called behavioural economics. Its representatives (D. Kahneman, A. Tversky, R. Thaler, M. Rabin and others) have proved that many assumptions of neoclassical and new classical models, based on homo oeconomicus scheme proposed by G.S. Becker, are not satisfied. In real situations people often do not calculate accurately, they also not always maximise their utility and are often not so egoistic as some economists predict ${ }^{1}$.

Psychological factors have constituted important part of J.M. Keynes' economic theory presented in his famous book "The General Theory of Employment, Interest and Money"2. According to his views effective demand and employment were determined by what he called the propensity to consume and the propensity to invest. He also thought that monetary phenomena are to a large extent psychological in their character. Interest rates are influenced by liquidity preference (propensity to money storing) that defines the quantity of assets held in a liquid form.

The propensity to consume (sensu stricte) might be defined as a 'slope of posture' towards products and services that increases the probability of their consumption. This attitude to propensities is different than Keynes' proposals. According to John M. Keynes the average propensity to consume could be understood as a share of consumption expenditures in income. This is rather the rate of consumption that depends on the propensity to consume (sensu stricte) but it is not necessarily identical with it.

J.M. Keynes conditioned what he called the propensity to consume on objective and subjective factors. The objective factors include the changes of wages unit, the changes of difference between income and net income, the unsuspected changes in owned capital, the changes of discount rate, fiscal policy and the expected relation between future and present income ${ }^{3}$. Subjective motives of consumption embrace pleasure, recklessness, lack of calculation, splendour and wastefulness. In case of the propensity to save, it is caution, foresight, interestedness, willingness to improve living conditions, independence, enterprise, pride and miserliness that are mentioned among subjective factors ${ }^{4}$.

J.M. Keynes thought that the propensity to consume depended both on objective and subjective factors. Nevertheless, the propensity to consume sensu stricte should be identified 
with subjective factors that affect economic phenomena independently. So called marginal propensity to consume is nothing more but the impact of income on consumption expenditures. The propensity to consume (sensu stricte) should be taken into account independently. The same is true in case of the remaining propensities (the propensity to save, invest and money storing).

J.M. Keynes connected propensity to invest with marginal efficiency of capital. A rate of investment is changing until it reaches the point where marginal efficiency of capital is equal to an interest rate. The propensity to invest depends on investment's demand and an interest rate. The probability of investment is also related with expectations which are shaped by psychological attitudes ('animal instincts'). J.M. Keynes also suggested that the propensity to invest depends on the types of entrepreneurs' characters.

What J.M. Keynes called the propensity to invest seems to be the investment rate that might depend on the propensity to invest sensu stricte. The propensity to invest (sensu stricte) consists of psychological factors that make the probability of investment higher, in given objective circumstances.

A liquidity preference sensu stricte (the propensity to thesaurisation) is a set of psychological traits that increases probability of storing assets in a liquid form. This attitude is also not consistent with J.M. Keynes' proposals. He thought that the propensity to thesaurisation depends on interest rates and the liquidity function.

To summarise, such propensities like the propensity to consume, save, invest or the propensity to thesaurisation (money storing) might have an important impact on economic processes so their influence should be taken into account. The propensities make allowance for psychological factors that often affect economic events significantly. The propensities should be understood as generalisation of psychological causes that increases the probabilities of events to happen in given objective circumstances.

\section{The analysis of the impact of propensities on commodity}

\section{and monetary markets equilibriums - a classical formulation}

In the classical model it is assumed that there is full employment and enterprises are maximizing profits in conditions of perfect competition ${ }^{5}$. Profits are being maximised when real wages are equal to marginal productivity of work. Money demand depends on the nominal value of production. Only a transactional motive $(L)$ appears. A speculative motive and money storing are set aside. 
The function of demand for money that gives consideration to the propensity to thesaurisation (money storing) could be written in the following form:

$$
L_{t}=k Y+s_{t}=L+s_{t}
$$

where:

$Y$ - nominal production,

$k=\lambda / V(\lambda-$ rate of multiplicity of nominal production, $V$ - speed of money circulation),

$s_{t}$ - additional demand for money as an impact of money storing.

In the equilibrium $L_{t}=M$, so the transactional demand for money is equal $L=M-s_{t}$. In the classical model it is presumed that money is exogenous so changes in money supply impact only inflation $(P)$ but not real economic variables. Therefore shifts in prices level could be related with the propensity to thesaurisation.

Because $Y=P y$ where $y$ is a real production and $L_{t}=k P y+s_{t}=M$, a price level is equal to $P=\left(M-s_{t}\right) /(k y)$. Money storing $\left(s_{t}\right)$ decreases the prices level for given $y$ and $k^{6}$. The propensity to thesaurisation does not affect the real sector of economy ${ }^{7}$.

In the classical model savings and investments depend on an interest rate that is adapting to a situation on the monetary market. Savings $(s)$ and investments $(i)$ functions with allowance for the propensity to invest $\left(s_{i}\right)$ and save $\left(s_{s}\right)$ take the following form: $i=i(r)+s_{i}$ and $s=s(r)+s_{s}$, where $r$ is an interest rate. According to the theory $i^{\prime}(r)<0, s^{\prime}(r)>0$.

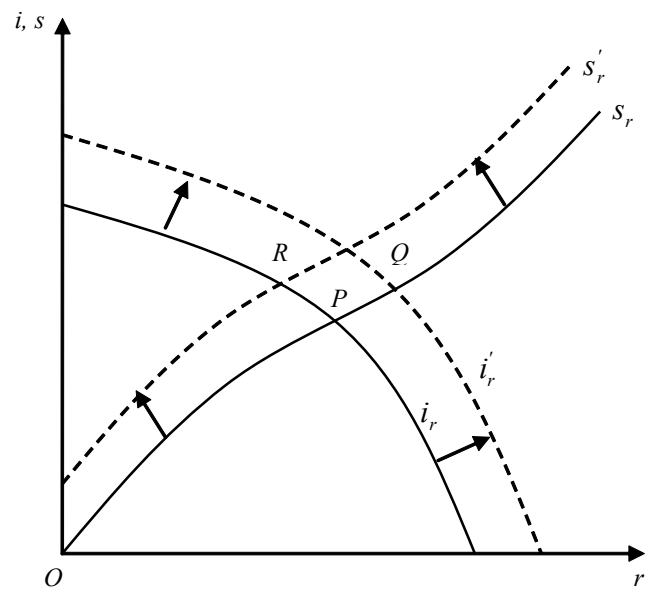

Fig. 1. The impact of the propensity to invest and the propensity to save on equilibrium in the classical model

Source: own studies based on Allen (1975), p. 117. 
The equilibrium state expressed as $i(r)+s_{i}=s(r)+s_{s}$ depends, beyond other factors, also on the propensity to invest and the propensity to save.

Higher propensity to invest increases investments, an interest rate and savings. The increase in the propensity to save makes savings and investments higher but the interest rate lower (Figure 1).

Higher propensity to invest shifts the investment function from $i_{r}$ to $i_{r}^{\prime}$. If the function of savings is not altered, the equilibrium changes from point $P$ to $Q$ where investments, savings and interest rate are higher. Increasing propensity to save, for a given investment function, changes the position of the saving function from $s_{r}$ to $s_{r}{ }_{r}$. In the new equilibrium $(R)$ savings and investments are higher but the interest rate is lower.

\subsection{Neoclassical Solow - Swan model}

The basic equation of the Solow model has the following form ${ }^{8}$ :

$$
\frac{d k}{d t}=s f(k)-(n+g+\delta) k
$$

where:

$d k / d t$ - changes of capital per unit of effective work in time $t$,

$k=K /(A L), A$ - parameter of efficiency, $K$ - resources of capital, $L$ - labour resources,

$s$ - exogenous rate of savings,

$f(k)$ - production function,

$n$ - constant rate of labour $(L)$ growth,

$g$ - constant rate of efficiency growth $(A)$ depending on knowledge, etc.,

$\delta$ - rate of capital depreciation.

The expression $s f(k)$ describes actual investments per unit of effective work while $(n+g+\delta) k$ represents restitution investments necessary to hold $k$ on the same level.

In the Solow - Swan model investments are related to the rate of savings $(s)$ that might depend also on the propensity to save $\left(s_{s}\right)$. It is a supply side model so such propensities as the propensity to consume, the propensity to invest or to money storing are not being taken into account directly.

The impact of the propensity to save shifts the actual investment function up from the position $s f(k)$ to $\left(s+s_{s}\right) f(k)$ (Figure 2). 


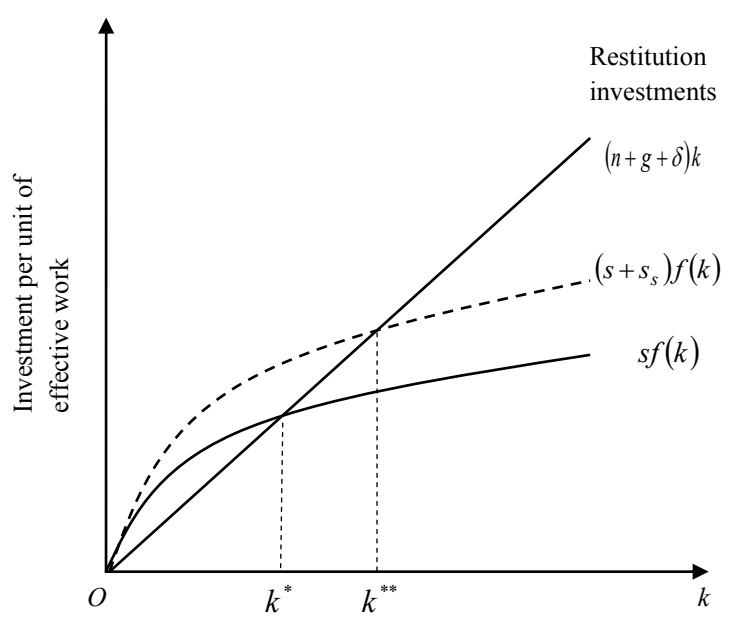

Fig. 2. The impact of the propensity to save on the equilibrium in the Solow - Swan model Source: own studies based on Romer (2000), p. 34.

Increasing propensity to save makes the $k$ ratio higher. The equilibrium is changing from $k^{*}$ to $k^{* *}$ where capital per unit of effective work is higher. The rate of the $k$ ratio growth is nevertheless the same. In the Solow model only technical progress leads to growing effects. All other changes evoke changes in levels only.

After few transformations it is possible to obtain influence of the growing propensity to save on product in long term:

$$
\frac{\partial y^{*}}{\partial s}=\frac{f^{\prime}\left(k^{*}\right) f\left(k^{*}\right)}{(n+g+\delta)-s f^{\prime}\left(k^{*}\right)}
$$

The relation (3) makes it possible to calculate the effect of the impact of the propensity to save on product per unit of effective work in the steady state growth.

It is also possible to extract a formula for elasticity of product per unit of effective work with respect to changes of the propensity to save (assuming as before that shifts in the rate of savings are the effects of influence of the propensity to save):

$$
\frac{\partial y^{*}}{\partial s} \frac{s}{y^{*}}=\frac{\alpha_{K}\left(k^{*}\right)}{1-\alpha_{K}\left(k^{*}\right)}
$$

where $\alpha_{K}\left(k^{*}\right)=k^{*} f^{\prime}\left(k^{*}\right) / f\left(k^{*}\right)$ is an elasticity of product due to capital per unit of effective work when $k=k^{*}$. 


\section{The analysis of the impact of propensities on the commodity and monetary markets equilibriums - the Keynesian frame}

In the Keynesian model there is no distinction between the real and monetary sector. All sectors are related and should be analysed simultaneously ${ }^{9}$. Consumption, savings and investments are mainly the functions of income. The relation between an investment and interest rate is deduced with respect to the concept of the marginal efficiency of investment.

In the context of the monetary market, beyond the transactional demand for money $L_{1}(Y)$ that depends on a nominal income $(Y)$ also a speculative motive $L_{2}(r)$ is taken into account, where $r$ is an interest rate. It is assumed that $L_{2}^{\prime}(r)<0$ and $L_{1}^{\prime}(Y)>0$.

The impact of the propensity to save (consume), invest and thesaurisation on the income $(Y)$ and the interest rate $(r)$ could be shown by means of the $I S$-LM scheme.
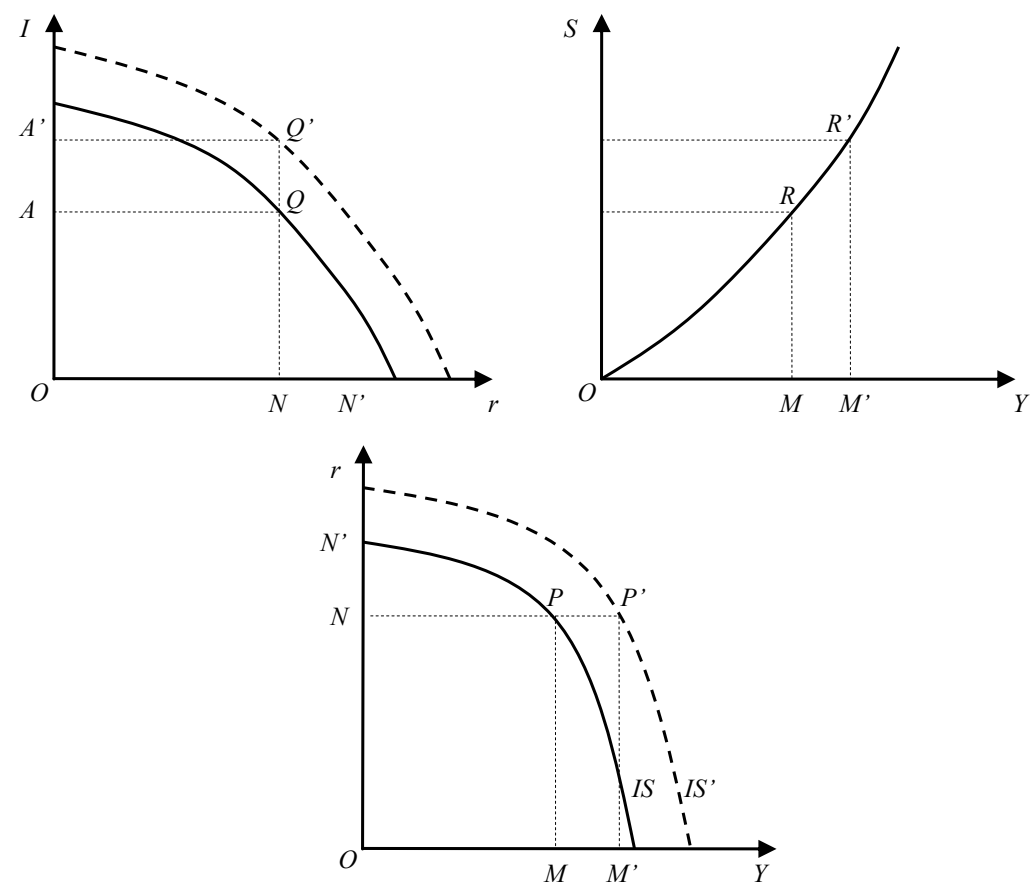

Fig. 3. The impact of the propensity to invest on income and interest rate (the $I S$ curve) Source: own studies based on Allen (1975), p. 126. 
Let us assume that investments $(I)$ and savings $(S)$ are equal to the length of the interval $O A$, the interest rate ( $r$ ) equals $O N$ and the income $(Y)-O M$ (Figure 3). $O N$ and $O M$ are coordinates of point $P$ on the $I S$ curve. Increasing propensity to invest makes investments higher for given values of interest rates (the investment function is moving up). If the propensity to save doesn't change, the investments are higher by $A A^{\prime}=Q Q^{\prime}$. The income is also growing by length of $M M^{\prime}$. All these changes result in the $I S$ curve moving right to the new position $I S$ ' where the income is higher than before for a certain interest rate. To sum up, the propensity to invest generally increases the income and the interest rate.
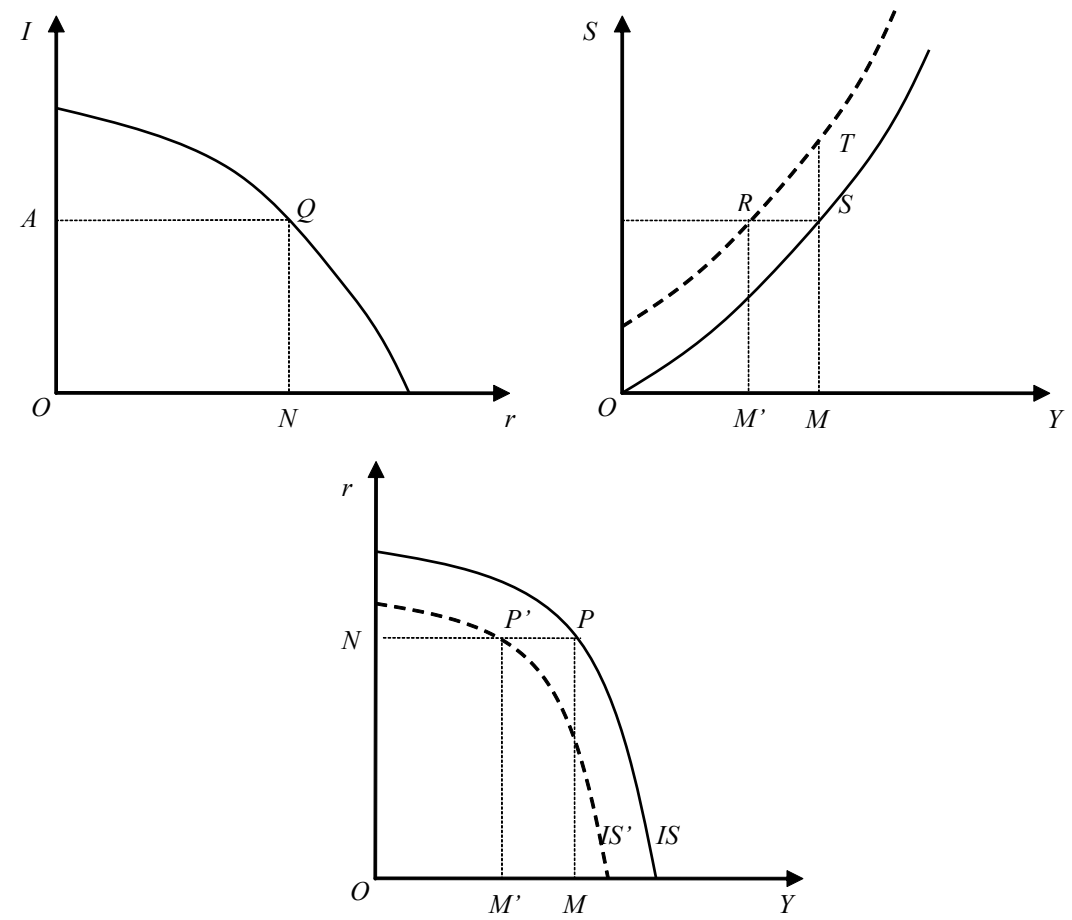

Fig. 4. The impact of the propensity to save on income and interest rate (the $I S$ curve) Source: own studies based on Allen (1975), p. 126.

Higher propensity to save moves the saving function up. Savings are higher for a given level of income (Figure 4). If the income equals $O M$, savings are higher by $S T$. Supposing that investment and savings are equal $O A$, the increase in the propensity to save changes the income from $M$ to $M^{\prime}$. When the propensity to save gets higher, the previous savings level is obtained for a lower income. The $I S$ curve is moving to the position $I S$ '. Income for a given interests rate 
is lower than before. Generally, the increase in the propensity to save makes the income as well as the interest rate smaller.

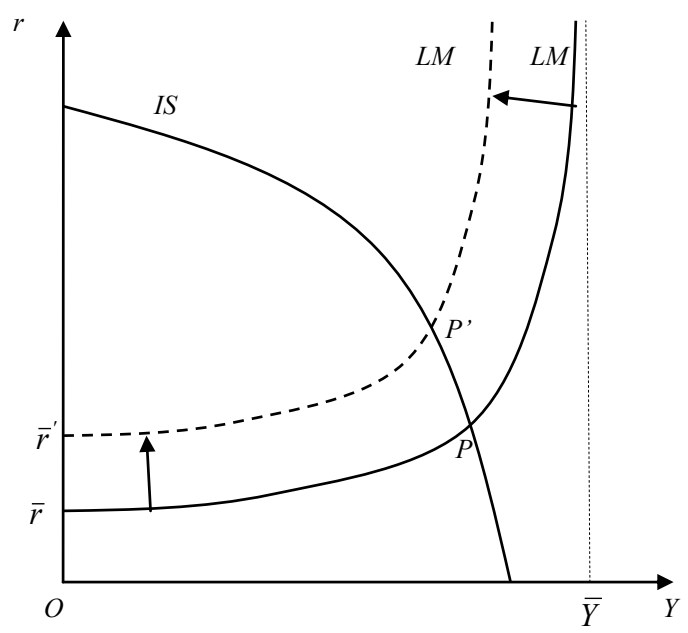

Fig. 5. The impact of the propensity to thesaurisation (money storing) on income and interest rate (IS-LM scheme)

Source: own studies based on Allen (1975), p. 127.

The increase in the propensity to thesaurisation moves the $L M$ curve to the left. The equilibrium is changing from the point $P$ to $P^{\prime}$ (Figure 5). In the new equilibrium the interest rate is higher and the income is lower.

An equation describing the monetary market with the allowance for the propensity to thesaurisation has the form of $M=L_{1}(Y)+L_{2}(r)+s_{t}$, where $L_{1}(Y)=k Y=k P y$. After transformations we know that $y=\left(M-L_{2}(r)-s_{t}\right) /(k P)$ and $P=\left(M-L_{2}(r)-s_{t}\right) /(k y)$. These equations show that the propensity to thesaurisation $\left(s_{t}\right)$ could decrease the real income $(y)$ and the price level $(P)$.

\section{Econometric methods of analyzing the impact of propensities on economic processes}

Subjective phenomena are usually unobservable but their influence in some cases is possible to determine. In general, the impact of propensities on economic phenomena could be estimated by adding dummy variables as the explanatory variables or by eliminating the impact of propensities from all the variables in the model ${ }^{10}$. These conclusions come from the Frisch - Waugh - Stone theorem ${ }^{11}$. 
Suppose that there is a following model:

$$
y=X_{1} \beta_{1}+X_{2} \beta_{2}+u
$$

where:

$y$ - vector of observations made on dependent variable,

$X_{1}, X_{2}$ - matrixes of observations made on explanatory variables where first matrix contains objectives factors and the second - dummy variables exhibiting subjective causes (propensities),

$u$ - error term.

The normal equations for (5) are:

$$
\left[\begin{array}{ll}
X_{1}^{\prime} X_{1} & X_{1}^{\prime} X_{2} \\
X_{2}^{\prime} X_{1} & X_{2}^{\prime} X_{2}
\end{array}\right]\left[\begin{array}{l}
\beta_{1} \\
\beta_{2}
\end{array}\right]=\left[\begin{array}{c}
X_{1}^{\prime} y \\
X_{2}^{\prime} y
\end{array}\right]
$$

so

$$
\hat{\beta}_{1}=\left(X_{1}^{\prime} X_{1}\right)^{-1} X_{1}^{\prime}\left(y-X_{2}^{\prime} \hat{\beta}_{2}\right)
$$

The estimates of the parameters next to the variables consisted in $X_{1}$ might be correctly calculated if the subjective factors $X_{2}$ are taken into account. Omitting the variables present in $X_{2}$ makes that $\hat{\beta}_{1}$ is biased by the factor $\left(X_{1}^{\prime} X_{1}\right)^{-1} X_{1}^{\prime} X_{2}^{\prime} \hat{\beta}_{2}$.

After a few transformations we know that:

$$
\hat{\beta}_{2}=\left(X_{2}^{\prime} M_{1} X_{2}\right)^{-1} X_{2}^{\prime} M_{1} y
$$

where $M_{1}=\mathrm{I}-X_{1}\left(X_{1}^{\prime} X_{1}\right)^{-1} X_{1}^{\prime}$ or equivalently:

$$
\hat{\beta}_{2}=\left(X_{2}^{* \prime} X_{2}^{*}\right)^{-1} X_{2}^{* \prime} y^{*}
$$

where $X_{2}^{*}=M_{1} X_{2}, y^{*}=M_{1} y$.

The equations (8) and (9) show that the impact of propensities could be estimated after eliminating the influence of variables being objective factors that appear in the matrix $X_{1}$.

\subsection{The determination of the impact of propensities by means of the residuals of econometric models for spatial data}

If we possess a priori statistical knowledge about a given propensity (in the form of variables) we could add such variables to econometric models as independent variables. The estimates of parameters next to such variables inform us about the impact of a given propensity on the 
analysed process. The propensities could be expressed as dummy $(0-1)$ variables equal one if a given object (a person, a collectivity) exhibits a propensity and zero otherwise. This a priori knowledge could originate from, for example, psychological or sociological studies.

In most cases we do not have a priori knowledge about propensities. So how could we operate in these kinds of situation?

Let us suppose that there is a following econometric model for spatial data:

$$
y_{i}=\alpha_{0}+\sum_{j=1}^{k} \alpha_{j} x_{j i}+u_{i}
$$

where:

$y_{i}$ - dependent variable,

$x_{j i}$ - independent variables (objective factors) $, j=1,2, \ldots, k$,

$\alpha_{j}$ - parameters $(j=0,1, \ldots, k)$,

$u_{i}$ - error term,

$i=1,2, \ldots, n, n-$ number of objects.

It is assumed that the model (10) contains all important objective factors. The impact of a given propensity could be analysed by means of dummy variables $d_{p}$ defined as follows:

$$
\left\{\begin{array}{l}
d_{p}=1 \text { if } p=i \\
d_{p}=0 \text { if } p \neq i
\end{array}\right.
$$

So the variable $d_{p}=1$ for the object $p$ and $d_{p}=0$ for all the remaining $(n-1)$ objects. The index $p$ equals respectively $1,2, \ldots, n$. All $d_{p}$ variables could not be added to the model (10) because the number of parameters would equal $k+1+n$ (we have $n$ variables $d_{p}$ ) which is greater than the number of observations $(n)$.

The following procedure enabling the analysis of the impact of propensities is proposed:

1) estimate $n$ models of the following type:

$$
y_{i}=\alpha_{0}+\sum_{j=1}^{k} \alpha_{j} x_{j i}+\gamma_{p} d_{p}+u_{i}
$$

where $p=1,2, \ldots, n$.

2) verify the following hypothesis in all $n$ cases:

$$
\begin{aligned}
& H_{0}: \gamma_{p}=0 \\
& H_{1}: \gamma_{p}>0
\end{aligned}
$$


If $H_{0}$ is rejected for the variable $d_{p}$, add this variable as an independent variable to the model (10).

After the addition of variables $d_{p}$ to the set of independent variables these two steps are repeated for the remaining dummy variables. The whole procedure stops when in all the considered cases there is no reason to reject $H_{0}$ or the degree of freedom is too small to add other dummy variables as independent variables.

After the implementation of this procedure we obtain an econometric model which takes into account the impact of a given propensity:

$$
y_{i}=\alpha_{0}+\sum_{j=1}^{k} \alpha_{j} x_{j i}+\sum_{l} \gamma_{l} d_{l}+u_{i}
$$

where $d_{l}$ stands for these variables $d_{p}$ for which the hypothesis $H_{0}$ in all the undertaken steps has been rejected.

\subsection{The econometric analysis of the impact of propensities on economic occurrences by means of models for cointegrated variables}

Many times series are integrated (and cointegrated) which has to be taken into account while analyzing the influence of propensities on economic processes ${ }^{12}$. Econometric tools proposed by the integration and cointegration methodology are important especially in the context of Lucas and Liu critiques as well as such issues as the exogeneity of variables and the spurious regression.

In case of a system consisting of two variables the coexistence relation could be presented as:

$$
y_{t}=\alpha_{0}+\alpha_{1} x_{t}+\alpha_{2} s_{t}+u_{t}
$$

where $u_{t}$ is a white noise process.

This is a very simple data generating process where values of $y_{t}$ are increased by the impact of a certain propensity that equals $\alpha_{2} s_{t}$.

The variable $s_{t}$ is a dummy variable that informs us if a given object (a person, a collectivity) exhibits the propensity in the period $t$. So $s_{t}=1$ if a given object shows the propensity in the period $t$ and $s_{t}=0$ otherwise. As we can see the impact of propensities in case of time series data (for one object) could be analysed only if a priori knowledge about a certain propensity is available. 
Let us suppose that the variable $x_{t}$ exhibits random walk with drift:

$$
x_{t}=\gamma+x_{t-1}+\xi_{t}
$$

where $\xi_{t}$ is an independently and identically distributed process with a zero mean and a constant variance.

The variables $y_{t}$ and $x_{t}$ are cointegrated if there is a linear combination that $y_{t}-\alpha_{0}-\alpha_{1} x_{t}$ $\sim I(0)$.

The equations (16) and (17) could be written in the VAR form:

$$
\left(\begin{array}{l}
y_{t} \\
x_{t}
\end{array}\right)=\left(\begin{array}{c}
\alpha_{0}+\alpha_{1} \gamma \\
\gamma
\end{array}\right)+\left(\begin{array}{cc}
0 & \alpha_{1} \\
0 & 1
\end{array}\right)\left(\begin{array}{c}
y_{t-1} \\
x_{t-1}
\end{array}\right)+\left(\begin{array}{cc}
\alpha_{2} & 0 \\
0 & 0
\end{array}\right)\left(\begin{array}{c}
s_{t} \\
0
\end{array}\right)+\left(\begin{array}{c}
u_{t}+\alpha_{1} \xi_{t} \\
\xi_{t}
\end{array}\right)
$$

The variable $y_{t}$ is related with $x_{t}$ and also depends on the exogenous variable $s_{t}$ that, according to the proposed hypothesis, informs about presence of given propensity in considered time periods.

The model (18) could be also written in the VECM form:

$$
\left(\begin{array}{c}
\Delta y_{t} \\
\Delta x_{t}
\end{array}\right)=\left(\begin{array}{c}
\alpha_{0}+\alpha_{1} \gamma \\
\gamma
\end{array}\right)+\left(\begin{array}{cc}
-1 & \alpha_{1} \\
0 & 0
\end{array}\right)\left(\begin{array}{c}
y_{t-1} \\
x_{t-1}
\end{array}\right)+\left(\begin{array}{cc}
\alpha_{2} & 0 \\
0 & 0
\end{array}\right)\left(\begin{array}{c}
\Delta s_{t} \\
0
\end{array}\right)+\left(\begin{array}{c}
u_{t}+\alpha_{1} \xi_{t} \\
\xi_{t}
\end{array}\right)
$$

In this model we have differences of a variable that show the presence of propensities $\left(\Delta s_{t}\right)$. Adding the variable $s_{t}$ to the model (19) would result as accumulation of the impact of propensities and this is rather unlikely.

The matrix $\boldsymbol{\Pi}$ takes the form:

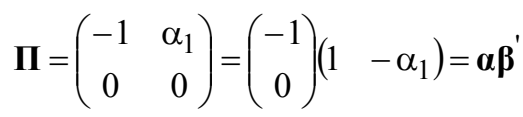

where $\alpha^{\prime}=\left(\begin{array}{ll}-1 & 0\end{array}\right)$ is an adjustment vector and $\beta^{\prime}=\left(1-\alpha_{0}\right)$ is a cointegrating vector. As we can see in the presented model $x_{t}$ is exogenous.

Depending on the deterministic component $\boldsymbol{\pi}$, five cases of such models are discussed in the literature ${ }^{13}$. The system VECM could be also written in a form where the variable $s_{t}$ is added to cointegrating space:

$$
\left(\begin{array}{c}
\Delta y_{t} \\
\Delta x_{t}
\end{array}\right)=\left(\begin{array}{c}
\alpha_{0}+\alpha_{1} \gamma \\
\gamma
\end{array}\right)+\left(\begin{array}{c}
-1 \\
0
\end{array}\right)\left(\begin{array}{lll}
1 & -\alpha_{1} & -\alpha_{2}
\end{array}\right)\left(\begin{array}{c}
x_{1, t-1} \\
x_{2, t-1} \\
s_{t}
\end{array}\right)+\left(\begin{array}{c}
u_{t}+\alpha_{1} \xi_{t} \\
\xi_{t}
\end{array}\right)
$$

The form (21) should be applied when the impact of a propensity on the variables $y_{t}$ and $x_{t}$ does not compensate and this is very likely in many cases. The presented simple models might be generalised to systems containing more variables. 


\subsection{Models for panel data as a tool of analyzing the impact of propensities}

In case of panel data the influence of propensities might be taken into account amongst others by means of models with fixed and random effects. A detailed description of these models and many useful tests could be found in Greene $(2003)^{14}$. In that kind of models it could be assumed that propensities modify individual effects ${ }^{15}$.

The fixed effects model could be written in the following form:

$$
y=X \beta+\mathrm{D} \alpha+\varepsilon
$$

where:

$y$ - vector of observations made on depended variable with size $n T \times 1(n-$ number of objects, $T$ - number of periods),

$\mathrm{X}$ - matrix consisting of observations made on ("objective") independent variables with size $n T \times k(k-$ number of independent variables $)$,

$\mathrm{D}$ - block diagonal matrix containing unitary vectors on main diagonal $(n T \times n)$,

$\alpha-$ vector of constant terms for all objects $(n \times 1)$,

$\varepsilon-$ vector of error terms $(n T \times 1)$.

The matrix D includes dummy variables that give possibility to take the impact of propensities into account. In case of models with fixed effects it is assumed that the influence of propensities modifies the estimates of individual effects consisted in the vector $\alpha$. It only makes sense when heterogeneity of the objects is due to propensities.

The model (22) does not have a common constant term $\alpha$. If we want to calculate the impact of propensities for a given object we have to find such differences as $\alpha_{i}-\alpha$, where $\alpha_{i}$ is an individual effect for the $i$-th object and $\alpha=\sum_{i=1}^{n} \alpha_{i} / n$ is a common constant term $(n-$ number of objects).

A model with random effects could be presented as:

$$
y_{i t}=\sum_{j=1}^{k} \beta_{j} x_{j i t}+\alpha+u_{i}+\varepsilon_{i t}
$$

$x_{j i t}(j=1, \ldots, k)$ - independent variables,

$\alpha$ - common constant term for all objects,

$u_{i}$ - realisations of random variable for $i$-th object (random effects),

$\varepsilon_{i t}-$ error term. 
In case of random effects model the impact of propensities is taken into account indirectly, in the process of parameters' estimation. A given propensity is taken into account by means of $u_{i}$ so a propensity manifests itself as a random variable.

\section{Conclusions}

It is important to be aware that economic occurrences depend also on subjective (psychological and sociological) factors. In many cases these causes could be identified with propensities. The influence of propensities is permanent and usually constant in reasonable time periods.

In the proposed concept propensities could be understood as generalised psychological and sociological causes that make the probabilities of certain events higher in a given objective circumstances. This proposal is different from most theories of propensities discussed mostly in the philosophy of science where propensities characterise not human psyche but whole situations $^{16}$.

In economics propensities are often identified with marginal or average propensities (to consume, save, invest). Marginal propensities usually show nothing more but the impact of income on other variables (consumption, savings and investments). So called average propensities could depend on the propensities sensu stricte but also on objective factors. The impact of propensities is often autonomous and should be analysed separately.

After accepting classical assumptions it could be stated that higher propensity to save increases investments and savings but decreases an interest rate. The growth of the propensity to invest makes investments, savings and an interest rate higher. The increase in the propensity to thesaurisation could reduce inflation but does not impact real aggregates.

In the Keynesian frame conclusions are in many cases different. The relation between the propensity to save as well as income and an interest rate is negative. Higher propensity to thesaurisation makes interest rates higher and income lower. The dependency between the propensity to invest and income even interest rate is positive.

The impact of propensities could by identified by means of econometric models. However the types of applied models are related with the nature of the data. In case of spatial data the impact of propensities might by analysed by using the models with dummy variables. For times series the data models that make allowance for cointegration (VAR, VECM) are useful. In case of panel data, models with fixed and random effects give an opportunity to set up the impact of propensities but a better alternative is to apply models for panel data cointegration. 


\section{Notes}

1 A detailed discussion encompassing these phenomena could be find in Rabin (1996), Doszyń (2008c).

2 Keynes (2003).

3 Ibidem.

4 Ibidem.

5 Allen (1975)

6 It suggests that the propensity to thesaurisation could lead to a lower inflation rate when money supply is increasing.

7 The propensity to thesaurisation is not identical with the propensity to saving. Saving is a wider category and could take different than liquid assets forms.

8 Romer (2000).

9 Allen, (1975).

${ }^{10}$ Dummy variable is equal 1 if object exhibits given propensity and 0 otherwise.

11 Greene (2003).

12 Problems connected with the analysis of integration and cointegration are presented in many econometric books and articles, see for example Johansen (2006), Johansen (1995), Juselius (2006), Hendry, Juselius (2001).

${ }^{13}$ See for example Johansen (2006), Hendry, Juselius (2001).

14 Greene (2003).

${ }^{15}$ It is worth to remember that the presented models for panel data do not take into account such issues as integration and cointegration. Models for cointegrated panel data seem to be more plausible here but they are not introduced in this article.

${ }^{16}$ Gillies (2000).

\section{References}

Allen, R.G.D. (1975). Teoria makroekonomiczna. Warszawa: PWN.

Doszyń, M. (2008a). Considerations concerning impact of propensities on basic macroeconomic variables. Folia Oeconomica Stetinensia, 2008/7(15).

Doszyń, M. (2008b). Metody analizy wpływu skłonności do konsumpcji na wydatki ludności. Wiadomości Statystyczne, 2008/9.

Doszyń, M. (2008c). Statystyczno-ekonometryczna analiza skłonności ludzkich. Szczecin: WNUS.

Fromm, E. (1999). Niech się stanie człowiek. Warszawa-Wrocław: Wydawnictwo Naukowe PWN.

Gillies, D. (2000). Varietes of Propensity. British Journal for the Philosophy of Science, 2000/51.

Greene, W. (2003). Econometric analysis. Fifth Edition. Prentice Hall. 
Hendry, D.F., Juselius, K. (2001). Explaining cointegration analysis: Part II. Energy Journal, 2001/22.

Hozer, J., Doszyń, M. (2004). Ekonometria skłonności. Warszawa: PWE.

Hozer, J. (2002). Ekonometryczna interpretacja skłonności w ekonomii. Przegląd Statystyczny, $2002 / 3$.

Jakimowicz, A. (2005). Od Keynesa do teorii chaosu. Warszawa: Wydawnictwo Naukowe PWN.

Johansen, S. (2006). Cointegration: a survey. In: Palgrave Handbook of Econometrics: Volume 1. Econometric Theory. Basingstoke, UK and New York, USA: Palgrave MacMillan.

Johansen, S. (1991). Estimation and hypothesis testing of cointegration vectors in Gaussian vector autoregressive models. Econometrica, 1991/59.

Johansen, S. (1995). Likelihood - based Inference in Cointegrated Vector Autoregressive Models. Oxford University Press.

Johansen, S. (1988). Statistical analysis of cointegration vectors. Journal of Economic Dynamics and Control, 1988/12.

Johansen, S. (2006). Statistical analysis of hypotheses on the cointegration relations in the I(2) model. Journal of Econometrics, 2006/132.

Johansen, S. (1994). The role of the constant and linear terms in cointegration analysis of nonstationary variables. Econometric Reviews, 1994/13.

Juselius, K. (2006). The cointegrated VAR model: Econometric methodology and macroeconomic applications. Oxford University Press.

Keynes, J.M. (2003). Ogólna teoria zatrudnienia, procentu i pieniądza. Warszawa: Wydawnictwo Naukowe PWN.

Keynes, J.M. (1946). The General Theory of Employment, Interest and Money. London: MacMillan and Co.

Maddala, G.S. (2006). Ekonometria. Warszawa: Wydawnictwo Naukowe PWN.

Popper, K.R. (1990). A World of Propensities. Bristol: Thoemmes.

Popper, K.R. (1959). The Propensity Interpretation of Probability. British Journal for the Philosophy of Science, 1959/10.

Rabin, M. (1996). Psychology and economics. Department of Economics, University of California - Berkeley.

Romer, D. (2000). Makroekonomia dla zaawansowanych. Warszawa: Wydawnictwo Naukowe PWN.

Samuelson, P.A. (1970). Foundations of Economic Analysis. New York: Atheneum.

Theil, H. (1979). Zasady ekonometrii. Warszawa: PWN. 